\title{
Rapid Analysis Method for Paraquat and Diquat in the Serum Using Ion-Pair High-Performance Liquid Chromatography
}

\author{
Mika Ito, ${ }^{*}, a$ Yasushi Hori, ${ }^{a}$ Manami Funsawa, ${ }^{a}$ Akira Oda, ${ }^{a}$ Shinichiro Katsuyama, ${ }^{a}$ \\ Yasuo Hirose, ${ }^{b}$ and Toshiharu YoshiokA ${ }^{c}$ \\ ${ }^{a}$ Department of Hospital Pharmacy, Niigata City General Hospital; ${ }^{b}$ Emergency and Critical Care Medical Center, \\ Niigata City General Hospital; 2-6-1 Shichikuyama, Niigata 950-8739, Japan: and ${ }^{c}$ Osaka General Medical Center; \\ 3-1-56 Bandai Higashi, Sumiyoshi-ku, Osaka 558-8558, Japan. \\ Received October 13, 2004; accepted January 20, 2005
}

In the present study, by using IPCC-MS3 (GL Sciences Inc. Tokyo, Japan) as the counter-ion in the mobile phase, we established a simple, quick method of analysis that separated and quantified paraquat and diquat on an ODS column by introducing the deproteinized serum sample directly into HPLC. The calibration curve of paraquat and diquat detected at UV $290 \mathrm{~nm}$ showed good linearity when the concentration of the injected sample was in the range $0.1-10.0 \mu \mathrm{g} / \mathrm{ml}$. The detection limit was $0.05 \mu \mathrm{g} / \mathrm{ml}$, and the mean recoveries $(n=5)$ added $1.0 \mu \mathrm{g} / \mathrm{ml}$ each of paraquat and diquat to standard serum were $87.5 \%$ and $89.1 \%$, respectively, while the RSD were $4.52 \%$ and $3.85 \%$. All of these were good results, and the time taken for one analysis was less than $30 \mathrm{~min}$. As a result of employing this analytical method for the analyses in four cases of acute poisoning, it was possible to decide promptly on treatment approaches for all of the present cases.

Key words paraquat; diquat; HPLC; acute poisoning; serum

In acute poisoning by herbicides containing paraquat, or paraquat and diquat, it is possible to infer from the concentration of paraquat in the serum whether the patient will or will not survive, and this is of importance as a basis for deciding what approach to take in emergency treatment. In Japan, the main emergency medical centers where acute poisoning is a specialty have HPLC-photodiode array systems installed for the purpose of toxin analysis. However, in the conventional HPLC method, since it is necessary as a preliminary procedure to extract the paraquat and diquat from serum samples, analysis is time-consuming, and the establishment of a faster analytical technique is a significant step.

To the knowledge of the authors, a wide variety of methods have been reported for determining the serum level of paraquat or diquat, for example, thin-layer chromatography, ${ }^{1)}$ spectrochemical analysis, ${ }^{2-8)}$ HPLC, ${ }^{9-21)} \mathrm{LC} / \mathrm{MS},{ }^{11} \mathrm{GC}^{22}$ and $\mathrm{GC} / \mathrm{MS}^{23)}$ In 1998, the Japanese Ministry of Health, Labor and Welfare distributed HPLC-photodiode array systems to 73 emergency centers throughout the country in order to facilitate the diagnosis of acute poisoning by drugs and poisons. The application of these HPLC systems was a highly practical step. However, since the task of extraction from samples has to be carried out for the conventional methods reported for HPLC analysis of paraquat, the establishment of a faster technique of analysis would be useful in order to minimize delay in reaching a diagnosis of poisoning by a paraquat preparation.

In the present study, after simply deproteinizing serum samples and introducing them directly to the HPLC column using an ion pair reagent as the mobile phase, we obtained good results with a new method that rapidly isolated and quantitated paraquat and diquat in an ODS column, and we report this and a number of cases in which analysis was actually performed.

\section{MATERIALS AND METHODS}

Reagents and Materials Paraquat dichloride $\left(1,1^{\prime}\right.$ dimethyl-4,4'-bipyridinium dichloride hydrate) from $\mathrm{RdH}$ Laborchemikalien $\mathrm{GmbH}$ \& Co KG (Germany), diquat dibromide (1,1'-ethylene-2,2'-bipyridylium dibromide monohydrate) were purchased from Wako Pure Chemicals (Osaka, Japan), and ethyl viologen dibromide (1,1'-diethyl4,4'-bipyridinium dibromide) was from Aldrich Chem. Co. (Milwaukee, WI, U.S.A.). These substances were dissolved in distilled water and were used as standard preparations. The ion-pair reagent IPCC-MS3 was purchased from GL Sciences Inc. (Tokyo, Japan). The distilled water was prepared by Wako Pure Chemicals (Osaka, Japan) for HPLC use, the acetone used was of special grade, and was manufactured by the same company, and the acetonitrile was a specially prepared reagent for HPLC produced by Nacalai Tesque, Inc. (Kyoto, Japan).

Biological Specimen Collection Standard human serum for recovery tests was purchased from Sigma Chemical Co. (St. Louis, MO, U.S.A.), and was stored at $-40^{\circ} \mathrm{C}$ until the time of analysis. The serum samples were derived from blood samples drawn from four patients poisoned by herbicides containing paraquat who ingested them with the aim of committing suicide and who were treated at the Emergency and Critical Care Center where the authors are employed. The serum samples were analyzed immediately upon acquisition.

Samples and Pretreatment Ten microliters of a $1000 \mu \mathrm{g} / \mathrm{ml}$ aqueous solution of ethyl viologen dibromide, the internal standard, was added to $1.0 \mathrm{ml}$ of serum, and this was followed by the addition of $1.0 \mathrm{ml}$ of acetone. The resulting solution was then mixed thoroughly on a vortex mixer, and separated for $5 \mathrm{~min}$ in a centrifuge at $2500 \mathrm{~g}$. After the supernatant fluid obtained was filtered through a filter with a pore size of $0.45 \mu \mathrm{m}$ (Ekicrodisc, Galman Sciences, Tokyo, Japan), $10 \mu \mathrm{l}$ of it was introduced into an HPLC. 
HPLC Conditions A sample that was infused into an HPLC instrument (SCL10A VP; Shimadzu; Kyoto, Japan) adjusted to a flow rate of $1.0 \mathrm{ml} / \mathrm{min}$ of the mobile phase of a $0.1 \%(\mathrm{v} / \mathrm{v})$ aqueous solution of IPCC-MS3/acetonitrile in the ratio $92 / 8$ was separated on an Inertsil ${ }^{\circledR}$ ODS-3 column (4.6 $\mathrm{mm} \times 150 \mathrm{~mm}, 5 \mu \mathrm{m}$ particle size; GL Sciences Inc., Tokyo, Japan) at a constant temperature of $40{ }^{\circ} \mathrm{C}$, and quantitative detection was carried out using a photodiode array detector (SPD-M10A VP Shimadzu; Kyoto, Japan) at a detection wavelength of UV290 nm. Quantitation was then performed by the internal standard method using analysis software (Class VP; Shimadzu, Kyoto, Japan).

Recovery Test Serum solutions (1 ml each) containing both paraquat and diquat at 10.0 or $1.0 \mu \mathrm{g} / \mathrm{ml}$ each were prepared by diluting $10 \mu \mathrm{l}$ each of paraquat and diquat standard solutions in $980 \mu \mathrm{l}$ of human standard serum. After internal standard solution was added and deproteinization was performed, the serum mixture was introduced into the HPLC column, and paraquat and diquat levels were measured by the internal standard method. The recovery rate was determined by subtracting the "noise" values obtained for standard human serum used as a "blank," to which no paraquat or diquat had been added, from the values obtained for the patient's serum sample; and then by calculating the ratios between these differences and the respective values determined for the mixed standard solution prepared so as to have a paraquat concentration of $10.0 \mu \mathrm{g} / \mathrm{ml}$ and a diquat concentration of $1.0 \mu \mathrm{g} / \mathrm{ml}$ ( $n=5$ for each concentration).

\section{RESULTS AND DISCUSSION}

HPLC Conditions Figure 1 presents a chromatogram showing separation on an Inertsil ODS-3 column after the introduction of $10 \mu \mathrm{l}$ of standard aqueous solution mixed so that the concentrations of paraquat and diquat were $1.0 \mu \mathrm{g} / \mathrm{ml}$, and that of the internal standard, ethyl viologen dibromide, was $10.0 \mu \mathrm{g} / \mathrm{ml}$. Figure 2 presents chromatograms resulting from the introduction to the HPLC (a) of $10 \mu \mathrm{l}$ of the supernatant of a deproteinized sample of standard serum only and (b) of a deproteinized standard serum sample with $1.0 \mu \mathrm{g} / \mathrm{ml}$ each of paraquat and diquat in which ethyl viologen dibromide was added to yield a concentration of $10.0 \mu \mathrm{g} / \mathrm{ml}$.

In the past, sodium heptane sulfonate, ${ }^{9,16,21)}$ and octane

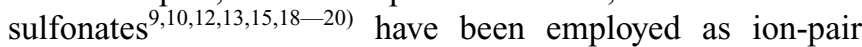
reagents for HPLC methods of determining serum paraquat levels, but pretreatment is necessary to apply these methods. Fuke et al. alone ${ }^{19)}$ have separated and assessed paraquat, diquat and metabolites of diquat in an ODS column by introducing serum diluted with distilled water directly into an HPLC system in which a mobile phase consisting of 5\% acetonitrile containing phosphoric acid $(0.2 \mathrm{M})$, ethylamine $(0.1 \mathrm{M})$, sodium octane sulfonate $(7.5 \mathrm{M})$ was used, but in a later paper, ${ }^{13)}$ they reassessed their findings, stating that solid-phase extraction is still necessary for the analysis of blood and tissues.

IPCC-MS3, which we used as the mobile phase, has a molecular weight of 214.04 , and a boiling point of $120^{\circ} \mathrm{C}$, and it is used as the ion-pair reagent with cation-releasing properties. ${ }^{24,25)}$ In the present study, by using a $0.1 \%(\mathrm{v} / \mathrm{v})$ aqueous solution of IPCC-MS3 and acetonitrile as the mo-

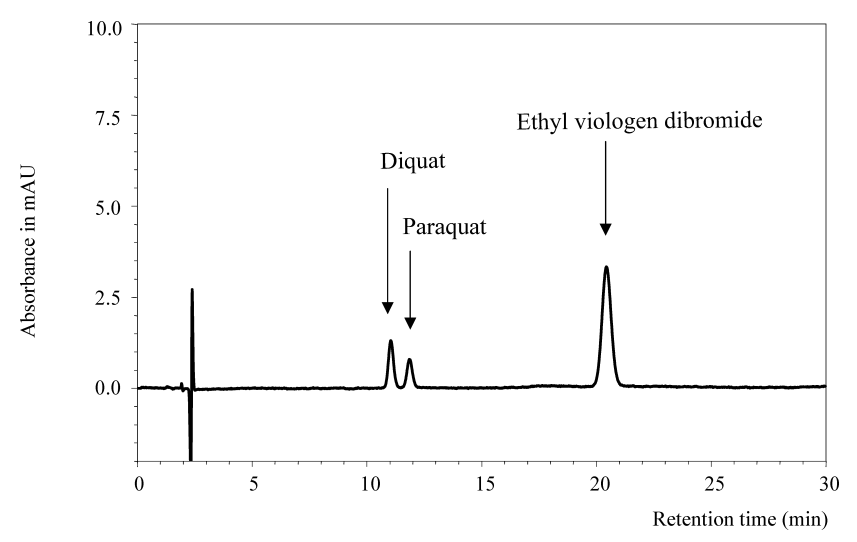

Fig. 1. HPLC Chromatogram of Standard Solution Mixed to Yield $1.0 \mu \mathrm{g} / \mathrm{ml}$ Concentrations of Both Paraquat and Diquat and a $10.0 \mu \mathrm{g} / \mathrm{ml}$ Concentration of Ethyl Viologen Dibromide (Internal Standard)

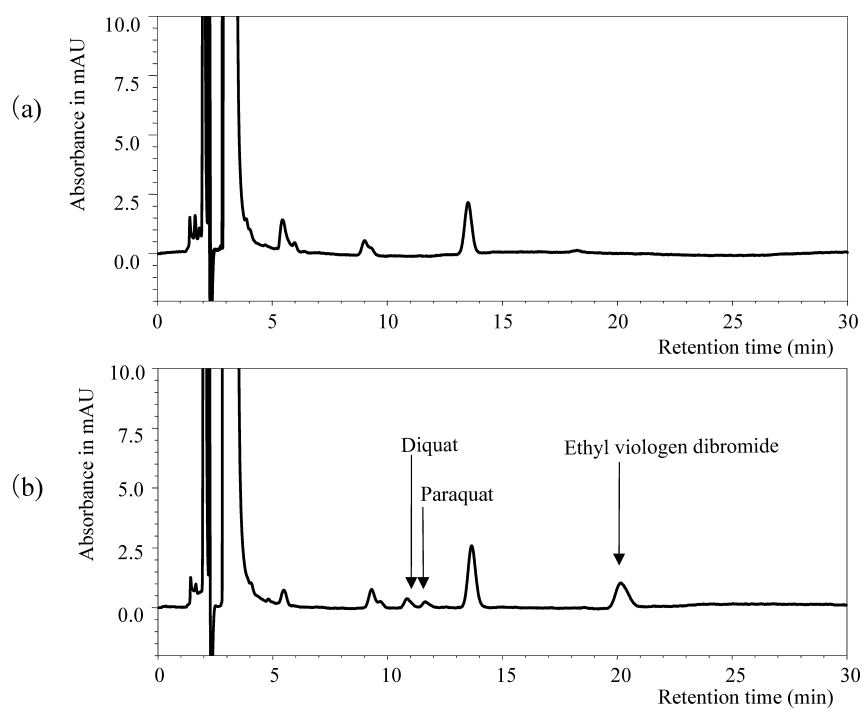

Fig. 2. HPLC Chromatograms of (a) Standard Serum, and (b) Standard Serum to Which Paraquat and Diquat Were Added to $1.0 \mu \mathrm{g} / \mathrm{ml}$ Each, Ethyl Viologen Dibromide (Internal Standard) to $10.0 \mu \mathrm{g} / \mathrm{ml}$

bile phase, we were able, without extraction procedures, to achieve good separation of paraquat and diquat from the components of the serum. Preparation of the mobile phase also was very simple, which is a great advantage in a clinical setting.

As for the calibration curves of paraquat and diquat generated at UV $290 \mathrm{~nm}$, regression lines $(y=0.63 x+0.0053$ and $y=0.42 x+0.0067)$ were obtained, the infused quantity of each substance being in the range $1-100 \mathrm{ng}$ (equivalent to concentrations of $0.1-10.0 \mu \mathrm{g} / \mathrm{ml}$ ), and the correlation coefficients were both 0.999 . When the signal-to-noise ratio was 5 , the detection limit was $500 \mathrm{pg}$ (a concentration of $0.05 \mu \mathrm{g} / \mathrm{ml}$ for both). According to the findings of Proudfoot et $a ._{.}{ }^{26)}$ and of Hart et al., ${ }^{27)}$ in order to assess whether the patient will survive after poisoning by herbicides containing paraquat, the lower detection limit of the blood concentration of paraquat should be $0.1 \mu \mathrm{g} / \mathrm{ml}$ or less. In the present method, because the samples are diluted by about 1 in 2 by the pretreatment procedure, the above condition is satisfied.

Moreover, the reproducibilities of the values determined for paraquat and diquat when a mixed standard solution con- 
Table 1. Recovery of Paraquat and Diquat from Serum Specimens

\begin{tabular}{lrcc}
\hline \hline & Added $^{a)}$ & Recovery & R.S.D $(\%)$ \\
\hline Paraquat & 10.0 & $98.9 \pm 2.33$ & 2.35 \\
& 1.0 & $87.5 \pm 3.95$ & 4.52 \\
Diquat & 10.0 & $88.4 \pm 1.73$ & 1.96 \\
& 1.0 & $89.1 \pm 3.43$ & 3.85 \\
\hline
\end{tabular}

a) Amounts are expressed as micrograms per milliliter. $b$ ) Values are mean \pm S.D. $(n=5)$

taining $1.0 \mu \mathrm{g} / \mathrm{ml}$ of each was analyzed were as follows: $\mathrm{RSD}=1.58 \%$ and $0.60 \%(n=5)$, respectively. The respective inter-day reproducibilities were $\mathrm{RSD}=3.40 \%$ and $1.12 \%$ $(n=5)$. Thus, the newly developed method was not only simple but also exhibited a good reproducibility.

Recovery Ratio Table 1 shows the results for recoveries calculated from the measured values after the addition of paraquat and diquat to human standard serum to obtain concentrations of $10.0 \mu \mathrm{g} / \mathrm{ml}$ and $1.0 \mu \mathrm{g} / \mathrm{ml}$, respectively.

In this procedure, the respective mean recoveries for paraquat and diquat after $1.0 \mu \mathrm{g} / \mathrm{ml}$ of each had been added were $87.5 \%$ and $89.1 \%$, the respective RSDs being $4.52 \%$ and $3.85 \%$. Kudo et al. ${ }^{9)}$ reported that, on adding paraquat and diquat to serum to yield a concentration of $1.0 \mu \mathrm{g} / \mathrm{ml}$ each, they obtained a recovery of $60 \%$; P. Paixao et al. ${ }^{12)}$ also reported adding paraquat to serum to give a concentration of $1.0 \mu \mathrm{g} / \mathrm{ml}$, and thereby achieving a recovery rate of $100.70 \%$ and an RSD of $4.36 \%$; while the report of Fuke et al. ${ }^{13)}$ stated that they added both paraquat and diquat for a concentration of $1.0 \mu \mathrm{g} / \mathrm{ml}$ of each in blood, and obtained respective recoveries of $83.7 \pm 4.8 \%$ and $83.8 \pm 4.2 \%$. Many conventional methods yield good recoveries, but the present technique, while demonstrating recoveries over $87 \%$ and repeatability with an RSD of $4.52 \%$, requires less than 30 minutes to perform for one analysis, which is clearly superior in terms of speed of execution than conventional methods that use solid-phase extraction, and is thus a useful method of analysis, especially in an emergency clinical setting.

Applications: Serum Analysis in Cases of Poisoning We applied this new method for the analysis of sera from a patient who had actually consumed herbicides containing paraquat. Figure 3 presents an HPLC chromatogram from the analysis of serum collected approximately $4 \mathrm{~h}$ after the subject ingested an unknown amount of the herbicide Priglox $\mathrm{L}^{\circledR}$, which contained $5.0 \%$ of paraquat and $7.0 \%$ of diquat. It was thus possible with this method to achieve good separation of paraquat and diquat.

Later, in 2003, four individuals fell victim to poisoning due to ingestion of paraquat-containing herbicide and were treated at our poison unit. Their data are listed in Table 2.

The observed serum paraquat concentration, when fitted to the survival probability curves of Hart et al. ${ }^{27}$, predicted that patients 1, 2 and 4 had survival probabilities of between 50 and $10 \%$, while that of patient 3 was less than $10 \%$. Ultimately, none of the patients survived. However, in both cases 2 and 3, the identity of the poison was not known definitely, but analysis quickly revealed that the patient had been poisoned by a herbicide containing paraquat. In the cases of patients 3 and 4 , the amount of poison ingested was not known, but since the concentration of paraquat in the serum of each patient could be quickly determined, it was possible

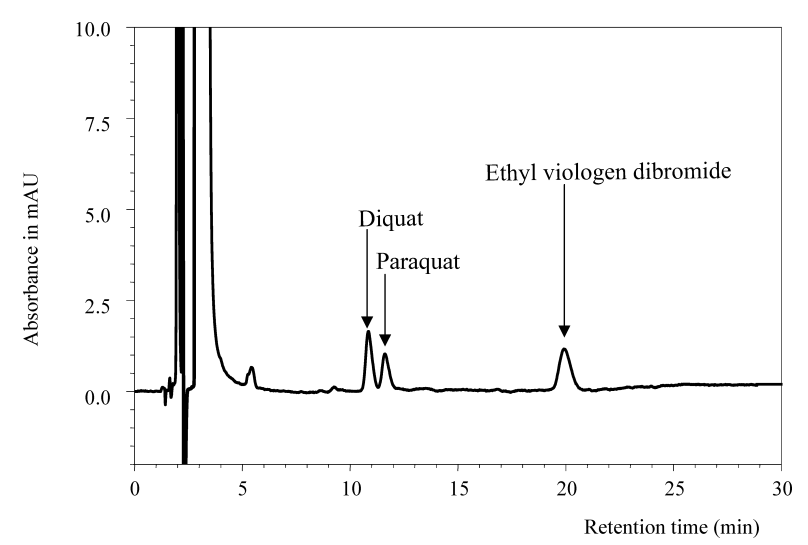

Fig. 3. HPLC Chromatographic Analysis of the Serum Drawn from the Patient about $4 \mathrm{~h}$ after Ingestion of the Herbicide Priglox $\mathrm{L}^{\circledR}$, which Contained $5.0 \%$ of Paraquat and $7.0 \%$ of Diquat

The concentrations of the paraquat and diquat in the serum were calculated to be 3.04 and $3.16 \mu \mathrm{g} / \mathrm{ml}$, respectively.

Table 2. Serum Paraquat Concentrations in Patients Intoxicated with a Paraquat-Containing Herbicide

\begin{tabular}{ccccc}
\hline \hline $\begin{array}{c}\text { Patient } \\
\text { number }\end{array}$ & Sex & Age (years) & $\begin{array}{c}\text { Time of } \\
\text { blood } \\
\text { collection }\end{array}$ & $\begin{array}{c}\text { Concentrations } \\
\text { of paraquat } \\
\text { in serum }\end{array}$ \\
\hline 1 & Man & 28 & $2 \mathrm{~h}$ & $8.75 \mu \mathrm{g} / \mathrm{ml}$ \\
2 & Man & 67 & $12 \mathrm{~h}$ & $1.09 \mu \mathrm{g} / \mathrm{ml}$ \\
3 & Man & 63 & $9 \mathrm{~h}$ & $13.8 \mu \mathrm{g} / \mathrm{ml}$ \\
4 & Woman & 84 & $4 \mathrm{~h}$ & $3.04 \mu \mathrm{g} / \mathrm{ml}$ \\
\hline
\end{tabular}

to assess the severity of their conditions.

As a result of new research, effective life-saving measures may be discovered against paraquat poisoning, and diagnoses and assessments of severity based on the present simple, rapid method of analysis will be a major factor in life preservation and the patient's survival.

\section{REFERENCES}

1) Van Den Heede M., Heyndrickx A., Timperman J., Med. Sci. Law., 22, 57-62 (1982).

2) Tayama J., Komatsu M., Doy M., Ohashi N., Ishizawa J., Mizutani T., Jpn. J. Toxicol., 4, 157-162 (1991).

3) Fuke C., Ameno K., Ameno S., Sogo K., Tsunenari S., Ogura S., Shirakawa Y., Oguri K., Ijiri I., Igakuno Ayumi, 143, 657-658 (1987).

4) Fell A. F., Jarvie D. R., Stewart M. J., Clin. Chem., 27, 286-292 (1981).

5) Jarvie D. R., Fell A. F., Stewart M. J., Clinica Chimica Acta, 117, $153-165$ (1981).

6) Kuo T. L., Lin D. L., Liu R. H., Moriya F., Hashimoto Y., Forensic Sci. Int., 121, 134-139 (2001).

7) Kuo T. L., Clin. Chem., 32, 337-339 (1986).

8) Fuke C., Ameno K., Ameno S., Kiriu T., Shinohara T., Sogo K., Ijiri I., J. Anal. Toxicol., 16, 214-216 (1992).

9) Kudo K., Namera A., Hori Y., Yamaguchi Y., Jpn. J. Toxicol., 16, 465-469 (2003).

10) Fuke C., Ameno K., Shirakawa Y., Ameno S., Kiriu T., Shinohara T., Ijiri I., Jpn. J. Toxicol., 5, 387-393 (1992).

11) Kage S., Kudo K., Fukushima S., Ikeda N., Jpn. J. Forensic Toxicol., 16, 34-41 (1998)

12) Paixao P., Costa P., Bugalho T., Fidalgo C., Pereira L. M., J. Chromatogr. B, 775, 109-113 (2002).

13) Fuke C., Arao T., Morinaga Y., Takaesu H., Ameno K., Miyazaki T., Legal Medicine, 4, 156-163 (2002).

14) Arys K., Van Bocxlaer J., Clauwaert K., Lambert W., Piette M., Van 
Peteghem C., De Leenheer A., J. Anal. Toxicol., 24, 116-121 (2000).

15) Madhu C., Gregus Z., Klaassen C. D., J. Chromatogr. B, 674, 193196 (1995).

16) Croes K., Martens F., Desmet K., J. Anal. Toxicol., 17, 310-312 (1993).

17) Nakagiri I., Suzuki K., Shiaku Y., Kuroda Y., Takasu N., Kohama A., J. Chromatogr., 481, 434-438 (1989).

18) Queree E. A., Dickson S. J., Shaw S. M., J. Anal. Toxicol., 9, 10-14 (1985).

19) Fuke C., Ameno K., Ameno S., Kinoshita H., Ijiri I., Arch. Toxicol., 70, 504-507 (1996).

20) Ameno K., Fuke C., Shirakawa Y., Ogura S., Ameno S., Kiriu T., Kinoshita H., Ijiri I., Arch. Toxicol., 68, 134-137 (1994).
21) Furusawa Y., Honjyo K., Yonemitsu K., Tsunenari S., Nippon Hoigaku Zasshi, 47, 57-62 (1993).

22) Kawase S., Kanno S., Ukai S., J. Chromatogr., 283, 231-240 (1984).

23) Draffan G. H., Clare R. A., Davies D. L., Hawksworth G., Murray S., Davies D. S, J. Chromatogr., 139, 311-320 (1977).

24) IPCC-MS3, "Manufacturer's Instructions," GL Sciences Inc., Tokyo, 1993.

25) Hori Y., Fujisawa M., Shimada K., Oda A., Katsuyama S., Wada K., Biol. Pharm. Bull., 27, 486-491 (2004).

26) Proudfoot A. T., Stewart M. S., Levitt T., Widdop B., Lancet, 2, 330332 (1979).

27) Hart T. B., Nevitt A., Whitehead A., Lancet, 2, 1222-1223 (1984). 